\title{
Interrelation Between the Changes of Phase Functions of Cardiac Muscle Contraction and Biochemical Processes as an Algorithm for Identifying Local Pathologies in Cardiovascular System
}

\author{
Yury Fedosov, Stanislav Zhigalov, Mikhail Rudenko, \\ Vladimir Zernov and Olga Voronova \\ New Russian University, \\ Russia
}

\section{Introduction}

Investigations of cardiovascular system based on mathematical models of hemodynamics developed by the authors allowed studying in details the cardiac cycle functions of different parts of the heart during different phases of the cardiac cycle. The proposed fundamentally novel diagnostic method based on phase analysis of cardiac cycle made it possible to track any functional and hemodynamic changes in the cardiovascular system. However, treatment of patients was always an issue after the diagnosis was established.

The existing understanding of the interrelations between the shape of the ECG an clinical meaning of the pathology were often in conflict with the insights gained from the phase analysis of cardiac cycle. New knowledge was needed about the processes occurring in the normal and pathological cardiovascular systems at the cellular level. The unique method of cardiac cycle phase analysis allowed verifying all the theoretical concepts based on the biochemical processes underlying development of the pathology, affecting functions of each segment of the cardiovascular system. Moreover, it proved possible to establish a number of recurring patterns of the influence of biochemical processes in the heart cells upon the observed shape of ECG and RHEOgrams.

In this chapter the authors outline their vision of the main biochemical processes determining the clinical meaning of the pathology diagnosed with the aid of the cardiac cycle analysis method. Selection of the therapeutic agents aimed at normalization of the diagnosed functional deviations taking into account the biochemical processes underlying these functions resulted in the recovery of the functions. 


\section{Interrelation between the contraction functions of myocardial muscles and biochemical processes in the cardiovascular system}

\subsection{Cardiac muscle contraction function and cell energy balance}

Investigations with the aid of cardiac cycle phase analysis have revealed a compensatory mechanism for maintaining normal hemodynamics [1]. The essence of the mechanism is that a decrease of the contraction phase function of one segment of the heart entails an increase of the contraction phase function in an adjacent segment. E. g., decrease of amplitude of contraction of the ventricular septum causes the amplitude of contraction of ventricles to increase. E. g., decrease of amplitude of contraction of the ventricular septum causes the amplitude of contraction of ventricles to increase. Such transformations of cardiovascular system can only be diagnosed with the aid of cardiac cycle phase analysis.

Without knowing the compensatory mechanisms, neither a precise localization of the pathology nor its controlled treatment is possible. Phase analysis taking into account the compensatory mechanisms and cause-and-effect relation logics also allows identifying the origin of the pathology. Elimination of the original cause of the disease results in normalization of functions of other segments that used to perform compensatory functions for the affected segment.

In this manner, the authors attempted to control the process of influencing local pathological zones. Assessment of the recovery of the affected segments revealed that the cause of the change of function was not in the degradation of conductivity of the cardiac electrical system, but in the biochemical processes taking place within the myocardial cells.

According to publications of other authors, there is a number of various factors affecting the effectiveness of myocardial cell recovery in terms of their energy supply functions and further normalization of the muscle contraction function. [2] I. Leontieva and V. Sukhorukov have introduced a new term - mitochondrial cardiomyopathy.

Mitochondria are the major consumers of oxygen in the body. Hypoxia resulting from insufficient saturation of blood with oxygen is causing tissue damage up to necrosis. The primary symptom of hypoxia is swelling of mitochondria. The mitochondria of heart muscles have anatomic specificities. These are associated with the increased intensity of oxidation processes occurring in the cardiovascular system. The main function of mitochondria is ATP synthesis based on the uptake of fatty acids, pyruvate, glucose and amino acids from cell cytoplasm and their oxidative cleavage with generation of $\mathrm{H} 2 \mathrm{O}$ и $\mathrm{CO} 2$. Fatty acids can only be delivered to mitochondria upon interaction with carnitine. Importantly, the quantative content of carnitine depends on the amount of secreted endorphins, thus regulating ATP synthesis. Besides that, carnitine regulates the exchange of phospholipids, essential substances required for normal function of the peripheral and central neural system. Its active form, Lcarnitine is used for treating anorexia, extreme exhaustion.

It is due to effective functioning of mitochondria that muscle contraction occurs. They are, however, the weakest link in the cell functioning. Hypoxia substantially alters their energy budget. Oxidative phosphorylation is inhibited, transferring the mitochondria into free operation mode. Normally, oxidation in mitochondria takes place aerobically. In case of ischemia, this process becomes anaerobic. Anaerobic processes also start to become predominant at the heart rates above 150 beats per minute. 


\subsection{Stress and functional phase changes}

In order to elucidate the influence of stress upon the work of heart and associated changes, normal energy supply to cardiac myocytes should be considered.

Contractility is the main function of cardiomyocytes. This is an energy dependent process requiring sufficient amount of ATP and $\mathrm{Ca}^{2+}$. Energy supply to heart cells is a complex of sequential processes, such as binding by carnitine and transportation into mitochondria of the oxidation products, ATP generation, its transportation and consumption in various energy-dependent reactions.

Following are the main specific features of the cardiomyocyte metabolism:

1. The metabolism is predominantly aerobic. The main route of energy generation is oxidative phosphorilation.

2. The main substrates of oxidation are fatty acids.

3. High rate of energy-dependent processes in the myocard.

4. Minimal inventory of high-energy compounds.

Metabolism of cardiomyocytes is predominantly aerobic. Thus, they receive most of the energy through electron transfer from organic substrates to molecular oxygen. Therefore, contraction function of the cardiac muscle is a linear function of the oxygen uptake rate $[3,4]$. Synthesis of molecular ATP occurs in the process of oxidative phosphorylation in mitochondria. The amount of ATP generated depends on the amount of acetyl-CoA (EC 6.4.1.2), which gets oxidized in the tricarbonic acid cycle. When myocard is normally supplied with oxygen, 60 to $80 \%$ of the acetyl-CoA is generated due to $\beta$-oxidation of fatty acids, and 20-30\% - in the course of aerobic glycolysis. As a result of one loop of tricarbonic acid cycle, one molecule of acetyl-CoA gets decomposed to $\mathrm{CO}_{2}$ and $\mathrm{H}_{2} \mathrm{O}, 38$ molecules of ATP being formed. Protons enter the mitochondrial respiratory chain in the form of reduced nicotineamides (NAD+ and $\mathrm{NADF}+$ ). The main sources of reducing agents and their interrelation with mitochondrial respiratory chain are illustrated in figure 1.

\section{$\beta$-fatty acids oxidation}

citric acid cycle

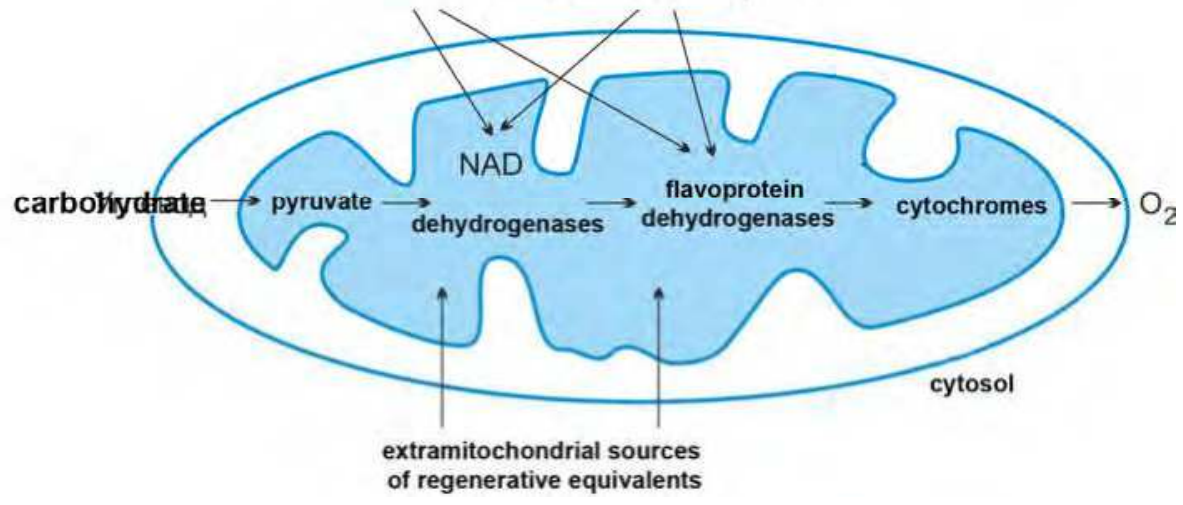

Fig. 1. The main sources of reducing agents and their interrelation with mitochondrial respiratory chain (NAD - nicotineamides). 
The main transporter of ATP in cardiomyocytes is creatine phosphate. ATP-ADP translocase transports ATP to the outer side of the inner mitochondrial membrane, where creatine is phosphorylated under the action of creatine kinase (EC 2.7.3.2). Thus, creatinine phosphate and ADP are generated. Thereafter, ADP is transported inside the mitochondrial membrane.

The most energy-consuming process in the cardiomyocyte is contraction of myofibrils. Translocation of counter-lateral actin filaments against myosin filaments towards the center of sarcomeres and formation of actin-myosin bridges in the myofibrils occurs when sufficient amount of ATP is present.

Having considered the energy balance of cardiomyocytes, let us move to the metabolic processes occurring under the conditions of local stress.

From the standpoint of heart muscle, stress primarily results in hypoxia. Lack of oxygen affects all the stages of the cell energy supply (synthesis, transportation and consumption of ATP). In order to compensate for this, cardiomyocyte mobilizes energy from the intracellular inventories and reduces energy consumption. The inventories of the energyrich substances - creatine phosphate, glucose and triglycerides are insignificant, and the cell soon starts to experience energy shortages. Anaerobic glycolysis is then activated to overcome the energy shortage.

Changes to fatty acid metabolism during hypoxia is characterized by disruption of $\beta$ oxidation of fatty acids, which is associated with the decrease of L-carnitine level caused by stress. Intracellular accumulation of fatty acids, acyl-carnitine and acyl-CoA (EC 6.2.1.3) occurs. The increase of acyl-CoA concentrations suppresses transportation of adenine nucleotides in mitochondria.

Development of hypoxia decreases the share of aerobic glycolysis to 5\%. Thus, under conditions of stress caused by lack of oxygen energy, energy supply in cardiomyocytes is reduced by $65-95 \%$ of its normal value. Anaerobic glycolysis is then activated to compensate for the energy deficiency. Generation of ATP is reduced to 2 molecules per a molecule of glucose (as compared to 38 molecules under normal conditions). Increase of the share of the anaerobic glycolysis covers about $60-70 \%$ of the energy consumption. However, if this compensation occurs for an extensive period, it becomes dangerous.

In the course of anaerobic glycolysis, lactate builds up causing lactic acidosis. Against this background, accumulation of ATP hydrolysis products, and free fatty acids causes intracellular acidosis. This is accompanied by the loss of integrity of lysosomal membranes, release of lysosomal ferments, which, under conditions of energy deficiency, results in the damage of mitochondria ultra structure.

The energy deficiency also contributes to loss of ion balance. Reduced concentration of ATP inhibits the $\mathrm{Na}^{+} / \mathrm{K}^{+}$pump of the cellular membranes. Consequentially, sodium and potassium ion concentration gradients start to decrease. Accumulation of sodium ions in the cardiomyocytes along with the increase of concentration of potassium ions in the extracellular solution result in the decrease of the resting potential and reduced duration of the action potential. Such deviations from the normal concentrations of ions in the intracellular and extracellular solutions cause hyperosmia, i.e. cell swelling, disrupting calcium homeostasis in the cardiomyocytes. Permittivity and contractility of certain sections of the cardiac muscle degrade, whereas neighboring parts of the cardiac muscle take 
additional load in a compensatory manner. These processes are clearly reflected in the cardiac cycle phases on the ECG. Relevant examples are given in the end of the chapter.

These abnormalities can be tracked with the aid of detecting functional phase contractions of the heart muscle.

\subsection{Neural pulse - Interaction with cells}

The influence of neural pulse on cardiac cells is associated primarily with initiation of sequential interrelated processes supporting cardiac muscle contraction.

Normal rhythmic contractions of cells occur as a result of spontaneous activity opf the pacemaker cells located in the sinoatrial node (SA node). Time interval between the heart contractions is determined by the time needed by the membranes of the pacemaker cells to reach the threshold level due to depolarization. Autonomous frequency of heart contractions is about 100 beats per minute without external impacts. An external impact is needed in order to increase or decrease this heart rate.

Vegetative neural system produces two most significant impacts on the heart beat rate. The fibers of both sympathetic and parasympathetic parts of the vegetative neural system terminate on the cells of the SA node and affect the heart rate beat. The impact is caused by a change of the process of spontaneous (autonomous) depolarization of the resting potential in the pacemaker cells of the sinoatrial node.

Acetylcholine released by parasympathetic neural fibers going to the heart as a part of branches of vagus nerve increases permeability of the membranes at rest to $\mathrm{K}^{+}$and decreases diastolic permeability for $\mathrm{Na}^{+}$. These changes of permeability have two effects on the resting potential of the pacemaker cells. Firstly, they cause initial hyperpolarization of the membrane resting potential, making it closer to the potassium equilibrium potential. Secondly, they decrease the rate of spontaneous depolarization of the membrane at rest. Both these effects tend to increase the lag between heart contractions due to increased period of depolarization of the resting membrane to the threshold value.

Sympathetic neural fibers release noradrenalin. The most essential effect of noradrenalin is the increase of the $\mathrm{Na}^{+}$and $\mathrm{Ca}^{2+}$ intake by the cell during the diastole. These changes increase heart beat rate due to increased rate of diastolic depolarization.

Besides the influence on the heart beat rate, vegetative neural fibers affect the rate of conduction of action potentials through heart tissues. Enhanced sympathetic influence increases the conduction rate, whereas the enhanced parasympathetic influence decreases the conduction rate of action potentials.

Cardiomyocyte contraction is initiated by the action potential signal to the intracellular organelles, resulting in increased tension and contraction of the cell. This process is known as excitation-contraction coupling. The key element of these processes is an abrupt increase of intracellular concentration of free $\mathrm{Ca}^{2+}$. Concentration of $\mathrm{Ca}^{2+}$ changes from less than 0.1 $\mathrm{mkm}$ at rest to $100 \mathrm{mkm}$ during maximal activation of the contraction machinery.

If we now recall the influence of local stress on cardiomyocytes and mechanisms of occurrence of this influence, the reasons behind and abnormalities in conduction and contraction of heart muscle become clear. 
When the energy transformation processes in the mitochondria become abnormal, parts of the respiratory chain are inhibited by specific therapeutic agents, chemical reagents or antibiotics, decrease of the amplitude of cardiomyocyte contraction due to lack of ATP is the first consequence to be observed. Thereafter, due to accumulation of free fatty acids, hydrolysis products, and lactate, due to development of internal acidosis and loss of ion balance of cell, conductance of action potential starts degrading, resulting not only in degraded conductivity of heart muscle and disturbance of the regulatory influence of the neural system on the work of heart as a whole.

\subsection{Endorphin stimulation as a natural way of enhancing stress resistance}

Having considered the specifics of biochemical processes taking place in stressed cardiac muscle, we can touch upon another important question: "How does the body fight stress?".

It is a common knowledge that when stress factors appear, all the systems of the body are activate. These processes are aimed at maintaining integrity, normal operability and survival of an organism. Regulation of the cascades of biochemical reactions occurring in response to stress factors is mediated by interactions of neural and endocrinal systems.

As shown in figure 2, as a result of stress the central neural system activates the following pathway of endocrinal regulation: hypothalamus - corticoliberin - pituitary gland adrenocorticotropic (AcTH) hormone - suprarenal gland - cortisol. Besides the adrenocorticotropic (AcTH) hormone, $\beta$-lipotropic hormone (LPH) is generated from the Cterminal part of the protein. LPH proteolysis results in generation of either $\gamma$-LPH and $\beta$ endorphin, or $\beta$-melanotropin and $\gamma$-endorphin. Beside that, LPH can decompose to aendorphin and met-enkephalin. Simultaneous production of all these hormones causes the following effects:

- Enhancement of carbohydrate metabolism (glucocorticoids)

- Enhancement of lipid metabolism (lipotropins)

- $\quad$ Reduced pain sensibility and euphoric sensation (endorphins and enkephalines)

- Stimulation of immune system (melanotropin).

Thus, there is a system of multiple regulatory signals initiated by a single stimulus regulating simultaneously a number of metabolic processes and receptor systems.

\subsection{Example of application of phase analysis of cardiac cycle for controlling recovery of the function of cardiovascular system in the course of treatment}

Based on our understanding of biophysical processes and having a tool for investigating phase processes of the heart function, we attempted to influence in an integrated manner the metabolic processes occurring in the myocardium and track the associated changes of the phase functions of heart contraction.

In order to influence the metabolism in an integrated manner, we performed normalization of the acid-base balance. L-carnitine and octolipen were used to affect lipid metabolism. Transcranial electrostimulation method was used in order to increase production of the pituitary gland hormones (adrenocorticotropic (AcTH) hormone, LPH, melanotropin, endorphins and enkephalines). 


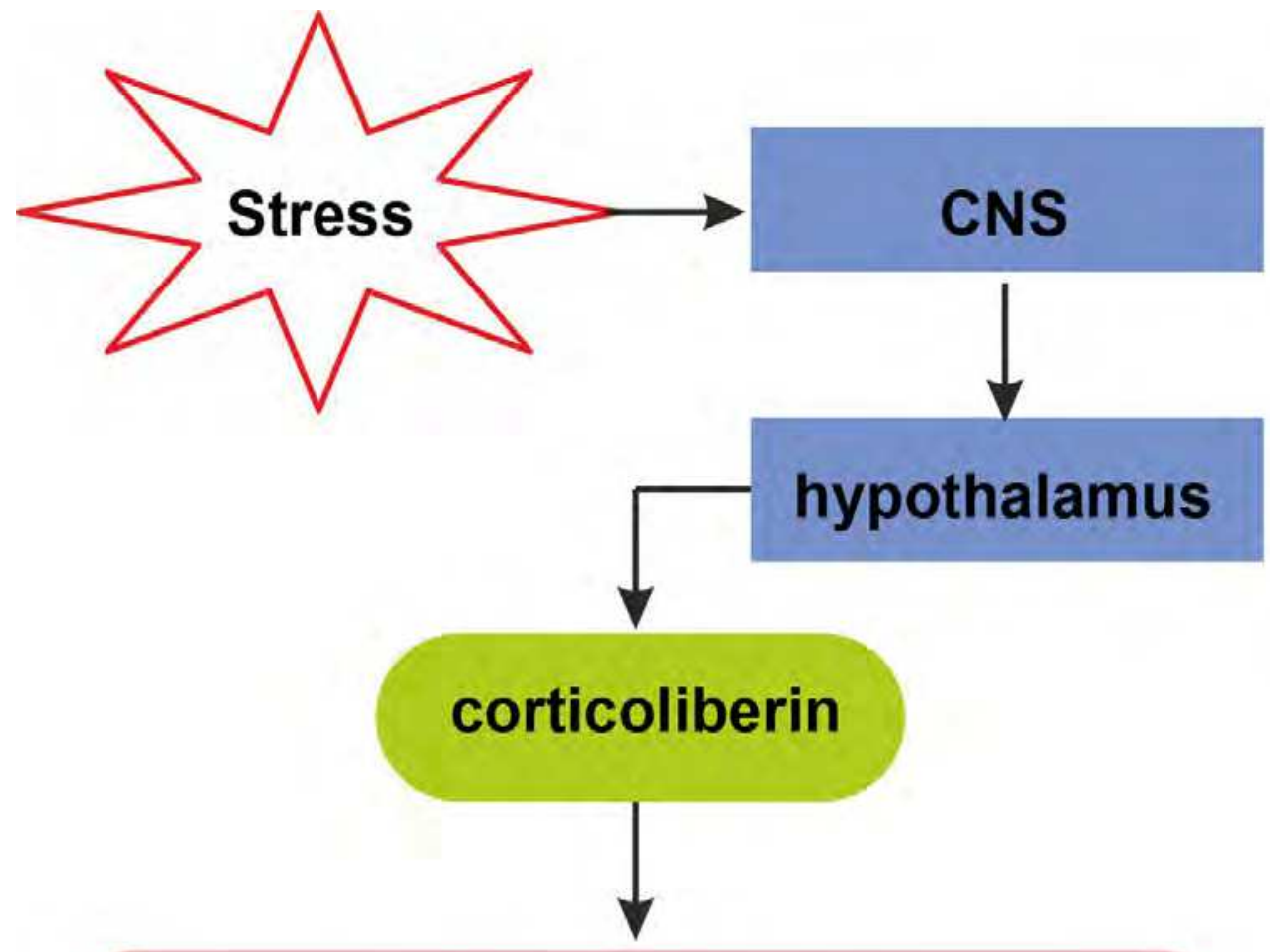

$\mathrm{N}-$

\section{protein precursor}

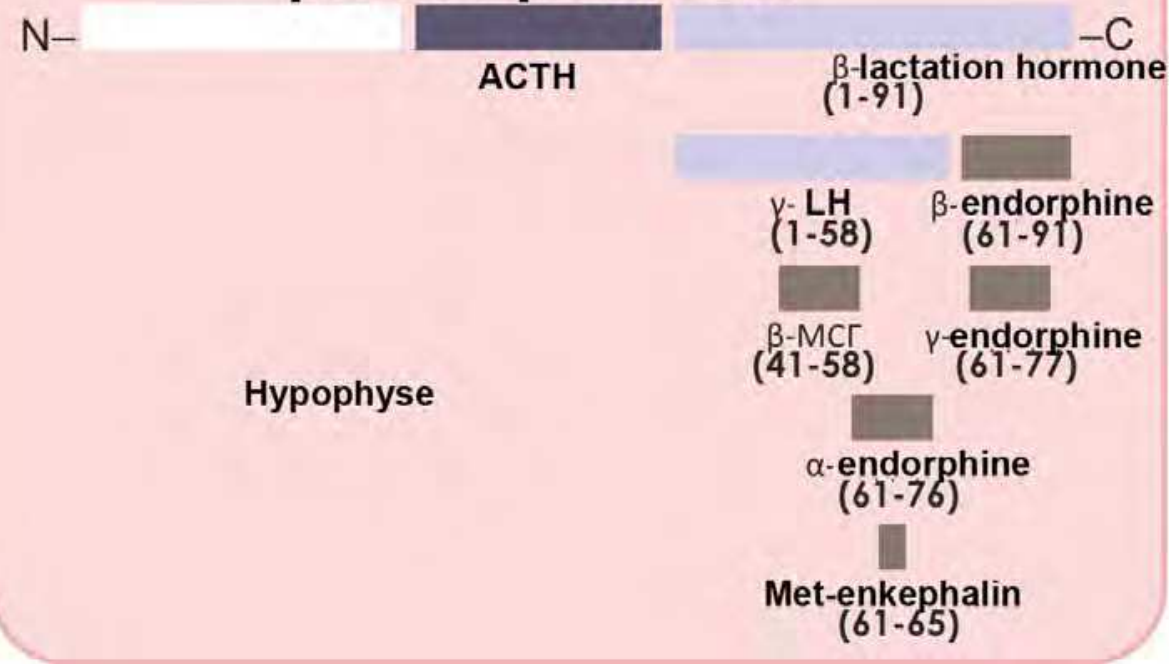

Fig. 2. Stimulation of the neuroendocrine regulation mechanism by stress 
During this study, we tracked not only changes of the cardiac phase functions, but also the phase hemodynamics parameters.

The results presented below were obtained in the course of integrated impact on the patient organisms.

The figure 3 illustrates the initial results. These are ECG and RHEO records of the ascending aorta and the table of the phase hemodynamics parameters. ECG and RHEO records correspond to the same cardiac cycle. For the sake of convenience, only one cardiac cycle is represented on the figure. The table summarizes results for 18 cardiac cycles. The number of cycles is not fixed during the recording. The duration of the record is about 20 seconds. This period is sufficient to obtain information for assessing hemodynamics parameters of several cardiac cycles.

The shape of ECG corresponds to Brugada syndrome. Interventricular septum lost its contraction function. This is evidenced by minimal amplitude of the R deflection. Expansion of the $\mathrm{S}$ deflection is a compensatory function. Having assumed increased contraction load, myocardial muscle increased its volume. Raise of SL wave on the ECG is indicative of increased arterial pressure. In this case, there is a continuous stress of myocardium since the amplitude of the SL phase is above the isoline in each cardiac cycle

The identified factors allow making conclusions and selecting the treatment strategy. The original cause is the issue with the interventricular septum, and it is this problem that has to be addressed. Widening of the $\mathrm{S}$ deflection and high amplitude of the SL phase are secondary factors caused by the compensatory mechanism of substitution of its lost function. In case of successful recovery of the function of the interventricular septum, other function are to normalize on their own.

There was an assumption that the problem of the loss of contractility function is based on mitochondrial cardiomyopathy. It was therefore decided that the patient should take Lcarnitine simultaneously with octolipen. In addition to that, daily use of the breathing

exerciser was prescribed in order to normalize the balance of carbon dioxide and oxygen in blood. These procedures were performed domiciliary. In the outpatient conditions, he was undergoing electrical treatment, excitation of specific cranial zones with small current pulses in order to stimulate release of endorphins. No limitations in diet were imposed.

According to the table on the figure 3 , in the beginning of the treatment the average value of the cardiac output (minute blood volume) of the patient ws MV $=9.71$ liters. In the course of treatment, MV variations from 7.63 to 10.93 liters were recorded.

In two months, the results presented in figure 4 were recorded. The record corresponds to the upright position of the patient body during orthostatic test. Splitting of the deflection $S$ is clearly visible. This is not a pathology, but rather a reaction of myocardium to overload. When the patient was in horizontal position, no splitting/vibrations were observed. However, already in the next cycle the ECG assumes fairly normal shape, though the shape is not yet stable. This is also evidenced both by the parameters of hemodynamics, namely the minute volume MV. 


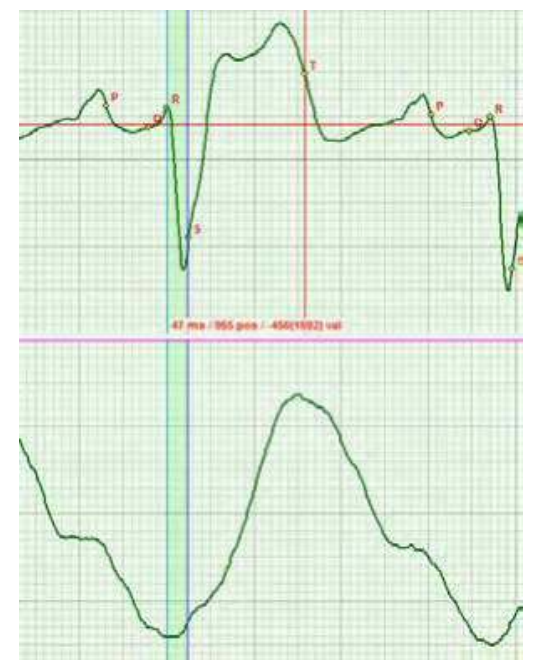

\begin{tabular}{|l|c|r|r|r|r|r|r|c|}
\hline \multicolumn{7}{|c|}{ PHASE ANALYSIS RESULTS } \\
\hline & \multicolumn{7}{|c|}{ HEMODYNAMIC PARAMETERS } \\
\cline { 2 - 8 } & SV(m) & MV(1) & PV1(ml) & PV2(m) & PV3(ml) & PV4(ml) & PV5(m) $)$ & $\begin{array}{c}\text { HEART } \\
\text { RATE }\end{array}$ \\
\hline AVERAGE & 140.01 & 9.71 & 83,25 & 56.76 & 83.23 & 56.78 & 14.98 & 69.39 \\
\hline
\end{tabular}

\begin{tabular}{|l|l|l|l|l|l|l|l|c|}
\hline CYCLE Ho & SV(ml) & MV(l) & PV1 $(\mathrm{ml})$ & PV2 $(\mathrm{ml})$ & PV3 $(\mathrm{ml})$ & PV4(ml) & PV5(m) & $\begin{array}{c}\text { HEAPT } \\
\text { RATE }\end{array}$ \\
\hline
\end{tabular}

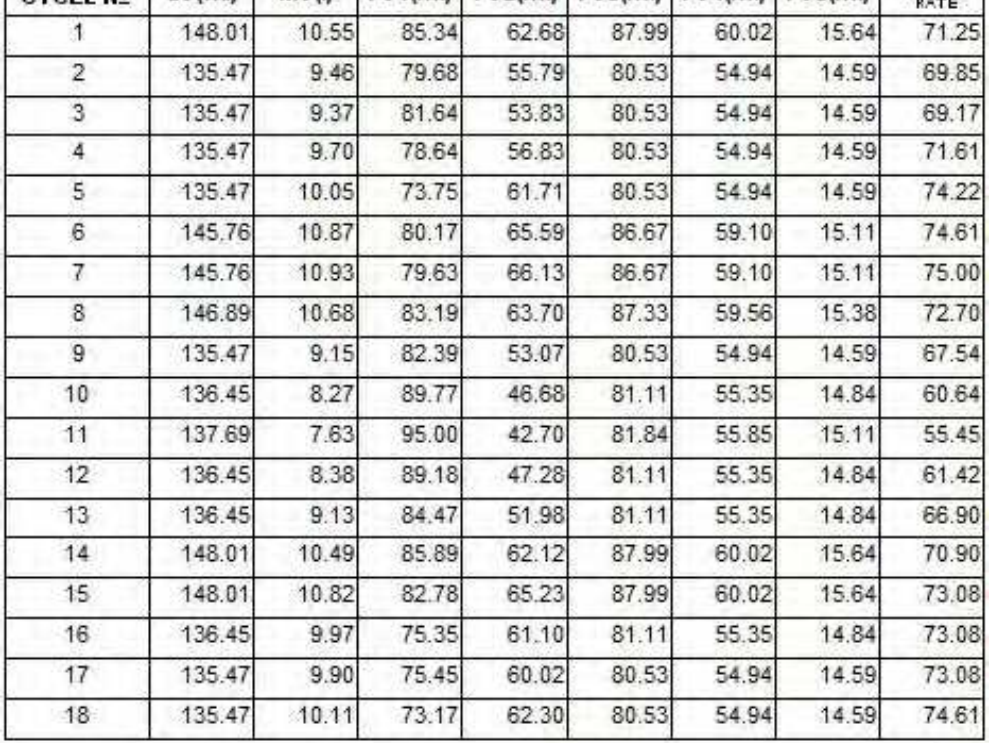

Fig. 3. September 2010 


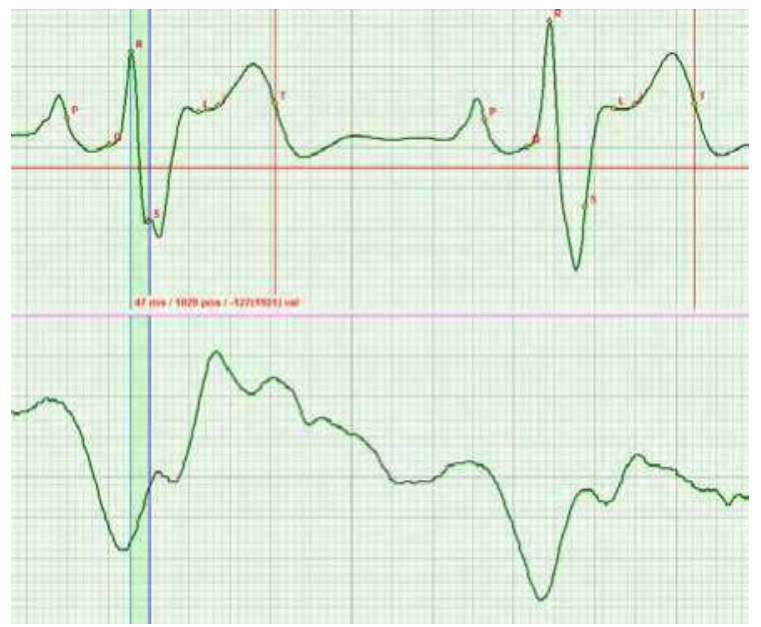

\begin{tabular}{|l|r|r|r|r|r|r|r|r|}
\hline \multicolumn{1}{|c|}{ PHASE ANALYSIS RESULTS } \\
\hline & \multicolumn{7}{|c|}{ HEMODYNAMIC PARAMETERS } \\
\cline { 2 - 9 } & SV(ml) & MV(l) & PV1(ml) & PV2(ml) & PV3(ml) & PV4(ml) & PV5(ml) & $\begin{array}{c}\text { MEAPT } \\
\text { PATE }\end{array}$ \\
\hline AVERAGE & 67.09 & 4.14 & 42.51 & 24.58 & 39.80 & 27.29 & 9.98 & 61.66 \\
\hline
\end{tabular}

\begin{tabular}{|c|r|r|r|r|r|r|r|r|}
\hline CYCLE II & SV(ml) & \multicolumn{1}{|c|}{ MV(l) } & PV1 $(\mathbf{m l})$ & PV2(ml) & PV3(ml) & PV4(ml) & PV5(ml) & $\begin{array}{c}\text { HEAPT } \\
\text { PATE }\end{array}$ \\
\hline 1 & 48.74 & 3.23 & 29.03 & 19.71 & 28.90 & 19.84 & 8.09 & 66.30 \\
\hline 2 & 48.74 & 2.94 & 31.43 & 17.31 & 28.90 & 19.84 & 8.09 & 60.34 \\
\hline 3 & 48.53 & 2.85 & 31.92 & 16.61 & 28.78 & 19.75 & 8.01 & 58.67 \\
\hline 4 & 152.74 & 9.18 & 98.66 & 54.08 & 90.80 & 61.94 & 16.28 & 60.10 \\
\hline 5 & 56.42 & 3.67 & 34.32 & 22.11 & 33.47 & 22.96 & 8.88 & 65.13 \\
\hline 6 & 56.70 & 3.71 & 34.20 & 22.50 & 33.63 & 23.07 & 8.98 & 65.42 \\
\hline 7 & 48.53 & 3.11 & 30.02 & 18.51 & 28.78 & 19.75 & 8.01 & 64.00 \\
\hline 8 & 48.53 & 2.94 & 30.99 & 17.54 & 28.78 & 19.75 & 8.01 & 60.59 \\
\hline 9 & 150.55 & 8.90 & 97.86 & 52.69 & 89.51 & 61.04 & 15.77 & 59.14 \\
\hline 10 & 48.33 & 2.93 & 31.22 & 17.11 & 28.66 & 19.67 & 7.93 & 60.59 \\
\hline 11 & 48.53 & 2.82 & 31.82 & 16.71 & 28.78 & 19.75 & 8.01 & 58.20 \\
\hline 12 & 56.42 & 3.18 & 37.94 & 18.48 & 33.47 & 22.96 & 8.88 & 56.43 \\
\hline 13 & 56.97 & 3.24 & 37.62 & 19.35 & 33.79 & 23.18 & 9.08 & 56.86 \\
\hline 14 & 149.44 & 9.28 & 94.17 & 55.27 & 88.85 & 60.59 & 15.51 & 62.12 \\
\hline 15 & 48.13 & 3.16 & 29.29 & 18.85 & 28.54 & 19.59 & 7.85 & 65.71 \\
\hline 16 & 48.33 & 3.23 & 28.39 & 19.93 & 28.66 & 19.67 & 7.93 & 66.90 \\
\hline
\end{tabular}

Fig. 4. November 2010

Another month later ECG remained unstable, but the average value of MV decreased to 9.06 liters. 


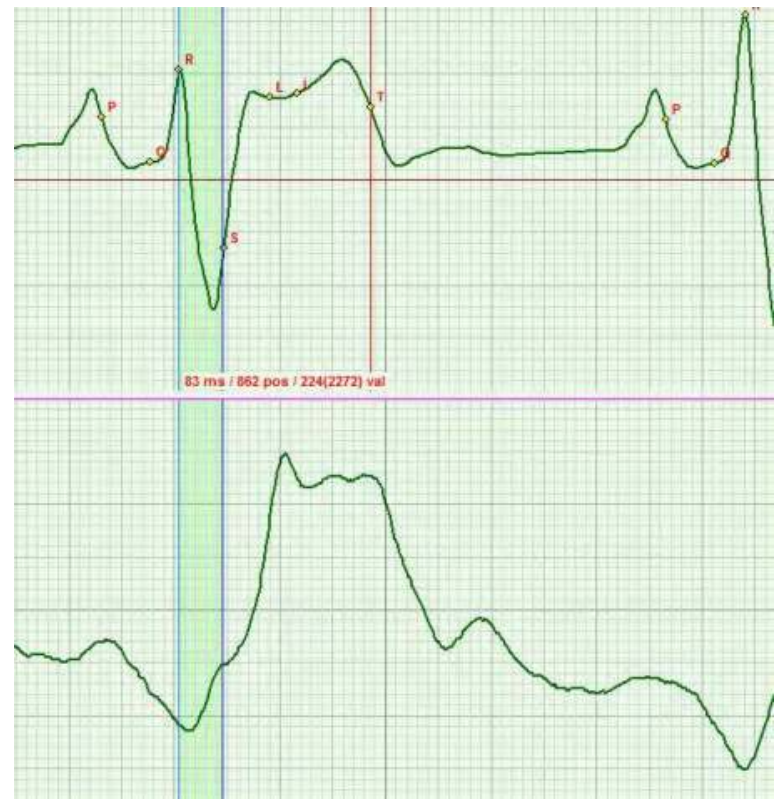

\begin{tabular}{|c|c|c|c|c|c|c|c|c|}
\hline \multicolumn{9}{|c|}{ PHASE ANALYSIS RESULTS } \\
\hline & \multicolumn{8}{|c|}{ HEMODYNAMIC PARAMETERS } \\
\hline & $\mathrm{SV}(\mathrm{ml})$ & MV(l) & PV1(m) & PV2(mi) & PV3(ml) & PV4(ml) & PV5(m) & $\begin{array}{l}\text { HEAPT } \\
\text { RATE }\end{array}$ \\
\hline AVERAGE & 144,47 & 9.06 & 93.81 & 50.66 & 85,86 & 58.60 & 15.89 & 62.74 \\
\hline
\end{tabular}

\begin{tabular}{|c|r|r|r|r|r|r|r|r|}
\hline CYCLE I & SV(ml) & \multicolumn{1}{|c|}{ MV(l) } & PV1(ml) & PV2(ml) & PV3(ml) & PV4(ml) & PV5(ml) & \multicolumn{1}{|c|}{$\begin{array}{c}\text { HEART } \\
\text { RATE }\end{array}$} \\
\hline 1 & 153.83 & 10.48 & 93.72 & 60.11 & 91.44 & 62.39 & 16.54 & 68.12 \\
\hline 2 & 143.42 & 9.22 & 90.88 & 52.54 & 85.23 & 58.18 & 15.98 & 64.27 \\
\hline 3 & 129.47 & 7.62 & 87.08 & 42.38 & 76.94 & 52.53 & 14.46 & 58.89 \\
\hline 4 & 152.81 & 9.18 & 101.82 & 50.99 & 90.84 & 61.97 & 16.29 & 60.09 \\
\hline 5 & 152.81 & 9.49 & 99.65 & 53.16 & 90.84 & 61.97 & 16.29 & 62.11 \\
\hline 6 & 153.83 & 9.47 & 101.72 & 52.11 & 91.44 & 62.39 & 16.54 & 61.59 \\
\hline 7 & 143.42 & 8.76 & 94.32 & 49.10 & 85.23 & 58.18 & 15.98 & 61.08 \\
\hline 8 & 129.47 & 8.18 & 83.24 & 46.22 & 76.94 & 52.53 & 14.46 & 63.17 \\
\hline 9 & 142.34 & 9.19 & 90.20 & 52.15 & 84.60 & 57.74 & 15.73 & 64.55 \\
\hline 10 & 154.89 & 9.87 & 100.00 & 54.89 & 92.07 & 62.82 & 16.80 & 63.71 \\
\hline 11 & 153.83 & 9.72 & 99.95 & 53.88 & 91.44 & 62.39 & 16.54 & 63.17 \\
\hline 12 & 131.22 & 8.15 & 85.82 & 45.40 & 77.97 & 53.24 & 14.91 & 62.11 \\
\hline 13 & 143.42 & 9.51 & 89.66 & 53.76 & 85.23 & 58.18 & 15.98 & 66.28 \\
\hline 14 & 153.83 & 10.06 & 97.17 & 56.66 & 91.44 & 62.39 & 16.54 & 65.40 \\
\hline 15 & 143.42 & 8.91 & 93.25 & 50.17 & 85.23 & 58.18 & 15.98 & 62.11 \\
\hline 16 & 132.29 & 7.82 & 89.90 & 42.39 & 78.60 & 53.68 & 15.16 & 59.12 \\
\hline
\end{tabular}

Fig. 5. December 2010

In two months, hemodynamics parameters grew somewhat. The patient continued to receive the treatment, having only excluded the octolipen. 


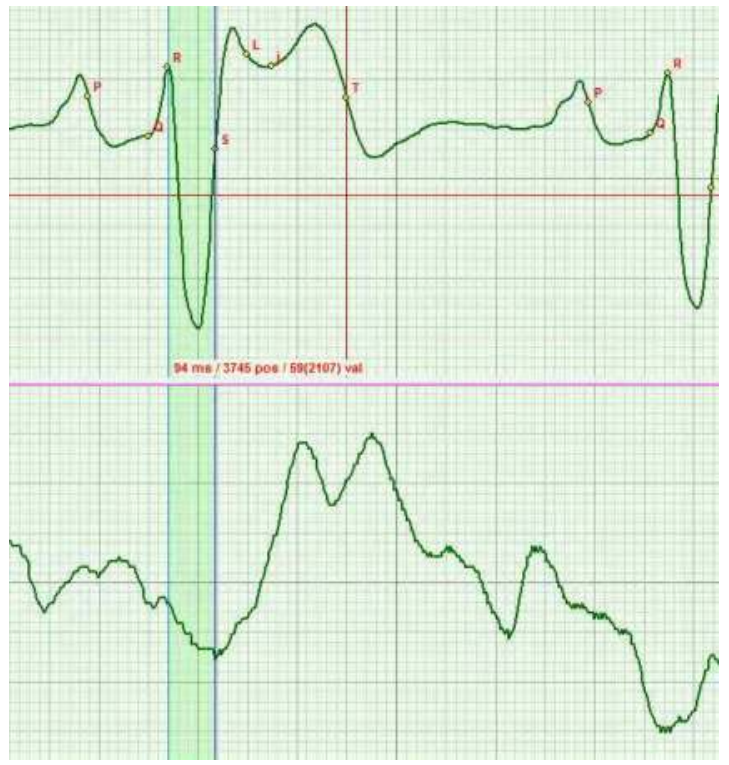

\begin{tabular}{|l|r|r|r|r|r|r|r|c|}
\hline \multicolumn{7}{|c|}{ PHASE ANALYSIS RESULTS } \\
\hline & \multicolumn{7}{|c|}{ HEMODYNAMIC PARAMETERS } \\
\cline { 2 - 8 } & SV(ml) & MV(l) & PV1(ml) & PV2(ml) & PV3(ml) & PV4(ml) & PV5(ml) & $\substack{\text { MEAPT } \\
\text { RAAT }}$ \\
\hline AVERAGE & 153.56 & 9.83 & 93.57 & 59.99 & 91.28 & 62.28 & 16.53 & 63.99 \\
\hline
\end{tabular}

\begin{tabular}{|c|c|c|c|c|c|c|c|c|}
\hline CYCLE N@ & $\mathrm{SV}(\mathrm{ml})$ & MV(I) & PV1(ml) & $\mathrm{PV} 2(\mathrm{ml})$ & PV3(ml) & PV4(ml) & PV5(ml) & $\begin{array}{l}\text { MEART } \\
\text { RATE }\end{array}$ \\
\hline 1 & 154.27 & 10.95 & 80.99 & 73.28 & 91.70 & 62.57 & 16.59 & 70.96 \\
\hline 2 & 154.27 & 10.35 & 90.02 & 64.25 & 91.70 & 62.57 & 16.59 & 67.09 \\
\hline 3 & 141.89 & 8.99 & 86.18 & 55.71 & 84.33 & 57.55 & 15.54 & 63.35 \\
\hline 4 & 163.53 & 10.59 & 99.38 & 64.15 & 97.23 & 66.29 & 16.83 & 64.74 \\
\hline 5 & 156.36 & 10.44 & 92.07 & 64.29 & 92.93 & 63.42 & 17.10 & 66.79 \\
\hline 6 & 153.25 & 10.62 & 85.26 & 67.99 & 91.10 & 62.15 & 16.34 & 69.30 \\
\hline 7 & 165.96 & 10.89 & 98.73 & 67.23 & 98.67 & 67.29 & 17.39 & 65.60 \\
\hline 8 & 142.76 & 8.97 & 87.05 & 55.71 & 84.85 & 57.91 & 15.77 & 62.81 \\
\hline 9 & 153.25 & 10.19 & 89.55 & 63.70 & 91.10 & 62.15 & 16.34 & 66.49 \\
\hline 10 & 155.34 & 10.66 & 89.07 & 66.27 & 92.33 & 63.00 & 16.85 & 68.65 \\
\hline 11 & 154.27 & 10.17 & 91.76 & 62.51 & 91.70 & 62.57 & 16.59 & 65.89 \\
\hline 12 & 145.65 & 8.46 & 94.29 & 51.36 & 86.55 & 59.10 & 16.49 & 58.11 \\
\hline 13 & 142.76 & 8.23 & 94.47 & 48,29 & 84.85 & 57.91 & 15.77 & 57.66 \\
\hline 14 & 154,27 & 9.77 & 96.32 & 57.94 & 91.70 & 62.57 & 16.59 & 63.35 \\
\hline 15 & 175.61 & 11.37 & 106.29 & 69.32 & 104.43 & 71.17 & 17.62 & 64.74 \\
\hline 16 & 153.25 & 9.46 & 96.84 & 56,41 & 91.10 & 62.15 & 16.34 & 61.76 \\
\hline
\end{tabular}

Fig. 6. February 2011

In another month the patient stated that he had gone through a medical exam in the regional clinics, where he was offered surgery to narrow the interventricular septum. The patient rejected the surgery. Coronary angiography was also performed, having indicated that the 
coronary arteries were clear. The patient was concerned with premature beats (extra systole). The figure 6 illustrates the original record made during investigation of phase parameters.

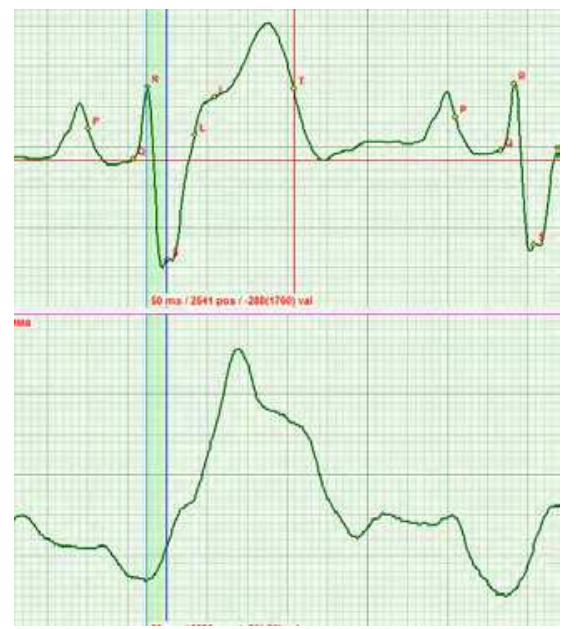

\begin{tabular}{|c|c|c|c|c|c|c|c|c|}
\hline \multicolumn{9}{|c|}{ PHASE ANALYSIS RESULTS } \\
\hline & \multicolumn{8}{|c|}{ HEMODYNAMIC PARAMETERS } \\
\hline & SV(ml) & $\operatorname{MV}(1)$ & $\mathrm{PV} 1(\mathrm{ml})$ & $\mathrm{PV} 2(\mathrm{ml})$ & $\mathrm{PV} 3(\mathrm{ml})$ & $\mathrm{PV} 4(\mathrm{ml})$ & PV5(ml) & $\begin{array}{c}\text { MEAPT } \\
\text { RANE }\end{array}$ \\
\hline AVERAGE & 56.32 & 3.86 & 33.18 & 23.14 & 33.40 & 22.92 & 9.09 & 68. \\
\hline
\end{tabular}

\begin{tabular}{|c|r|r|r|r|r|r|r|r|}
\hline CVCLE II & SV(ml) & MV(l) & PV1(ml) & PV2(ml) & PV3(ml) & PV4(ml) & PV5(ml) & $\begin{array}{c}\text { AEART } \\
\text { PATE }\end{array}$ \\
\hline 1 & 65.80 & 4.57 & 37.86 & 27.95 & 39.03 & 26.77 & 10.08 & 69.44 \\
\hline 2 & 66.13 & 4.59 & 38.46 & 27.67 & 39.23 & 26.90 & 10.19 & 69.44 \\
\hline 3 & 41.15 & 2.82 & 23.94 & 17.21 & 24.40 & 16.76 & 7.29 & 68.48 \\
\hline 4 & 56.92 & 4.07 & 31.21 & 25.72 & 33.76 & 23.16 & 9.07 & 71.45 \\
\hline 5 & 48.92 & 3.46 & 27.45 & 21.47 & 29.01 & 19.91 & 8.21 & 70.77 \\
\hline 6 & 65.80 & 4.55 & 39.22 & 26.58 & 39.03 & 26.77 & 10.08 & 69.12 \\
\hline 7 & 57.18 & 3.88 & 34.32 & 22.86 & 33.91 & 23.27 & 9.16 & 67.85 \\
\hline 8 & 66.45 & 4.39 & 40.63 & 25.83 & 39.42 & 27.04 & 10.30 & 66.03 \\
\hline 9 & 48.92 & 3.17 & 29.85 & 19.07 & 29.01 & 19.91 & 8.21 & 64.87 \\
\hline 10 & 49.16 & 3.29 & 29.74 & 19.41 & 29.15 & 20.01 & 8.30 & 66.93 \\
\hline 11 & 65.80 & 4.49 & 39.25 & 26.56 & 39.03 & 26.77 & 10.08 & 68.16 \\
\hline 12 & 66.45 & 4.47 & 39.83 & 26.62 & 39.42 & 27.04 & 10.30 & 67.23 \\
\hline 13 & 48.92 & 3.30 & 29.47 & 19.45 & 29.01 & 19.91 & 8.21 & 67.54 \\
\hline 14 & 48.69 & 3.33 & 28.78 & 19.91 & 28.87 & 19.82 & 8.08 & 68.48 \\
\hline 15 & 48.92 & 3.41 & 28.41 & 20.51 & 29.01 & 19.91 & 8.21 & 69.77 \\
\hline 16 & 57.65 & 3.95 & 33.85 & 23.80 & 34.19 & 23.46 & 9.34 & 68.48 \\
\hline 17 & 57.42 & 3.97 & 33.03 & 24.39 & 34.05 & 23.37 & 9.25 & 69.12 \\
\hline 18 & 75.60 & 5.23 & 45.30 & 30.30 & 44.85 & 30.75 & 11.24 & 69.12 \\
\hline
\end{tabular}

Fig. 7. March 2011

After a series of sit-ups, extra systole was detected (see Fig. 8). Minute volume MV increased to 13.66 liters. 

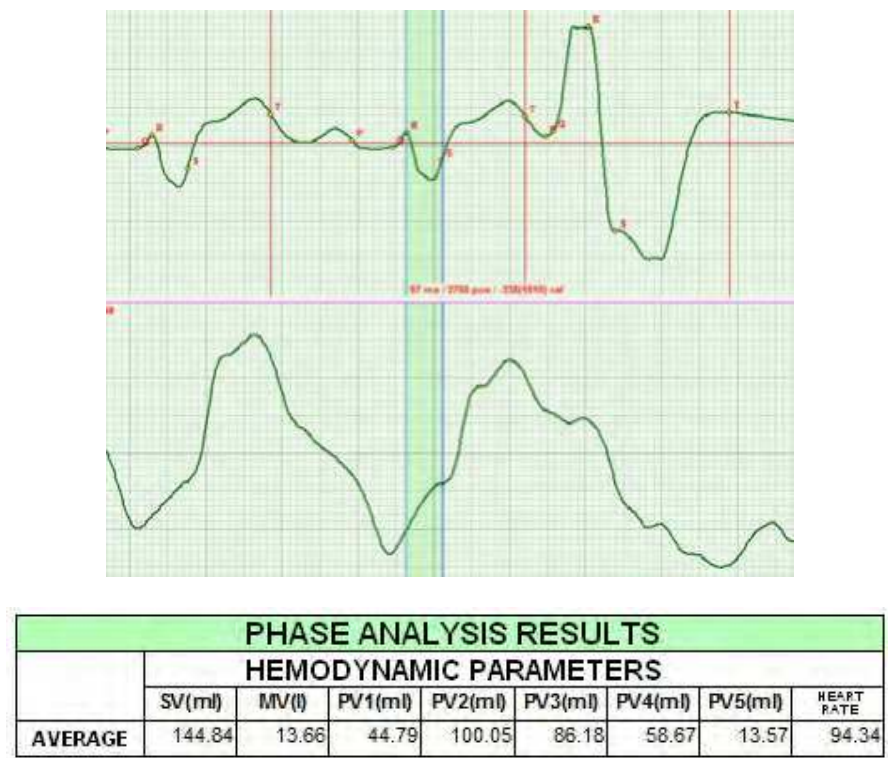

\begin{tabular}{|l|l|l|l|l|l|l|l|c|}
\hline CYCLE No & SV(mi) & MV(l) & PV1 $(\mathrm{ml})$ & PV2 (ml) & PV3(ml) & PV4(ml) & PV5 (ml) & $\substack{\text { MEART } \\
\text { RATE }}$ \\
\hline
\end{tabular}

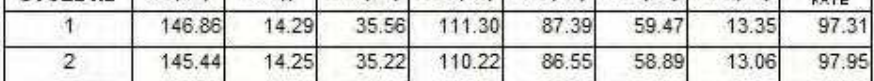

\begin{tabular}{|c|c|c|}
\hline 3 & 128.32 & 114 \\
\hline
\end{tabular}

\begin{tabular}{|r|r|r|r|r|r|r|r|r|}
\hline 4 & 137.00 & 13.16 & 40.04 & 96.95 & 81.51 & 55.49 & 12.81 & 96.04 \\
\hline 5 & 157.02 & 14.89 & 42.67 & 114.35 & 93.46 & 63.57 & 13.89 & 94.81 \\
\hline
\end{tabular}

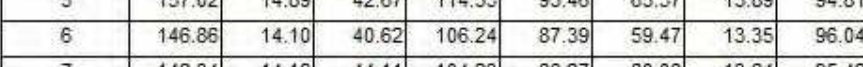

\begin{tabular}{|l|r|r|r|r|r|r|r|r|}
\hline 7 & 148.34 & 14.16 & 44.11 & 104.23 & 88.27 & 60.08 & 13.64 & 95.42 \\
\hline 8 & 157.02 & 14.98 & 43.43 & 113.59 & 93.46 & 63.57 & 13.89 & 95.42 \\
\hline
\end{tabular}

\begin{tabular}{|r|r|r|r|r|r|r|r|r|}
\hline 9 & 155.43 & 14.74 & 44.67 & 110.75 & 92.51 & 62.92 & 13.58 & 94.81 \\
\hline 10 & 148.34 & 13.80 & 52.30 & 96.05 & 88.27 & 60.08 & 13.64 & 93.02 \\
\hline 11 & & & & &
\end{tabular}

\begin{tabular}{|c|c|c|c|c|c|c|c|c|}
\hline 11 & & & & & & & & \\
\hline & & & & & & & & \\
\hline 12 & 129.46 & 11.75 & 50.68 & 78.78 & 77.00 & 52.46 & 12.74 & 90.74 \\
\hline 13 & 148.34 & 13.38 & 58.08 & 90.27 & 88.27 & 60.08 & 13.64 & 90,19 \\
\hline 14 & 148.34 & 13.54 & 57.40 & 90.94 & 88.27 & 60.08 & 13.64 & 91.30 \\
\hline 15 & 146.86 & 13.75 & 49.14 & 97.72 & 87.39 & 59.47 & 13.35 & 93.61 \\
\hline 16 & 148.34 & 13,89 & 47.64 & 100.71 & 88.27 & 60.08 & 13.64 & 3.6 \\
\hline 17 & 148.34 & 13.80 & 49.61 & 98.74 & 88.27 & 60.08 & 13.64 & 93.02 \\
\hline 18 & 114.25 & 13.20 & 346.18 & -231.93 & 67.85 & 46.41 & 14.42 & 115.55 \\
\hline 19 & 129.46 & 9.97 & 76.18 & 53.29 & 77.00 & 52.46 & 12.74 & 77.04 \\
\hline 20 & 130.74 & 11.94 & 48.42 & 82.32 & 77.75 & 52.98 & 13.01 & 91.30 \\
\hline 21 & 149.67 & 14.19 & 41.37 & 108.29 & 89.05 & 60.62 & 13.92 & 94.8 \\
\hline 22 & 148.34 & 14.34 & 35.92 & 112.42 & 88.27 & 60.08 & 13.64 & 96.67 \\
\hline 23 & 157.02 & 15.28 & 35.05 & 121.97 & 93.46 & 63.57 & 13.89 & 97.3 \\
\hline 24 & 146.86 & 14.39 & 36.28 & 110.57 & 87.39 & 59.47 & 13.35 & 97.95 \\
\hline 25 & 131.94 & 12.59 & 37.20 & 94.75 & 78.47 & 53.48 & 13.27 & 95.42 \\
\hline 26 & 140.70 & 13.34 & 35.93 & 104.77 & 83.69 & 57.01 & 13.61 & 94.8 \\
\hline 27 & 148.34 & 14.06 & 40.33 & 108.01 & 88.27 & 60.08 & 13.64 & 4. \\
\hline
\end{tabular}

Fig. 8. March 2011, after sit-ups having caused extra systole. 
After relaxation of the patient, the extra systoles disappeared. MV $=13.32$.

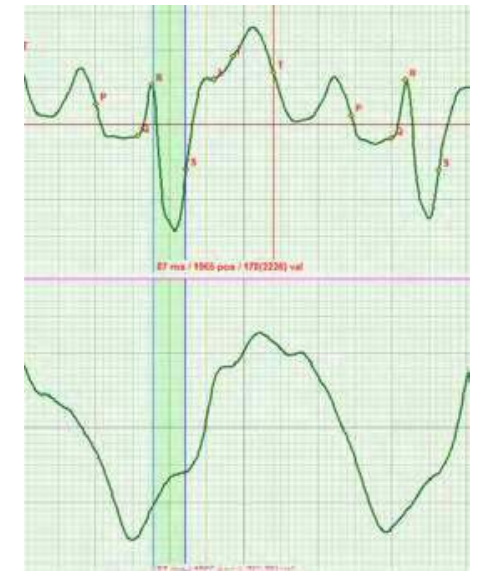

\begin{tabular}{|c|c|c|c|c|c|c|c|c|}
\hline \multicolumn{9}{|c|}{ PHASE ANALYSIS RESULTS } \\
\hline & \multicolumn{8}{|c|}{ HEMODYNAMIC PARAMETERS } \\
\hline & $\mathrm{SV}(\mathrm{mll})$ & MV(I) & PV1 $(\mathrm{ml})$ & \begin{tabular}{|l|}
$\mathrm{PV} 2(\mathrm{ml})$ \\
\end{tabular} & PV3(ml) & PV4(ml) & PV5 (mi) & $\begin{array}{l}\text { MEAPT } \\
\text { RATE }\end{array}$ \\
\hline AVERAGE & 147,45 & 13.32 & 48.56 & 98.89 & 87.71 & 59.75 & 14.34 & 90.30 \\
\hline CYCLE INo & $V(\mathrm{ml})$ & MV(I) & PV1 (ml) & PV2(ml) & PV3(ml) & PV4(ml) & PV5(mi) & $\begin{array}{l}\text { HEAPT } \\
\text { RATE }\end{array}$ \\
\hline 1 & 149.91 & 14.20 & 38.36 & 111.55 & 89.20 & 60.72 & 13.95 & 94.74 \\
\hline 2 & 161.90 & 14.95 & 43.35 & 118.55 & 96.34 & 65.56 & 14.83 & 92.3 \\
\hline 3 & 164.84 & 15.32 & 42.90 & 121.93 & 98.07 & 66.77 & 15.43 & 92.95 \\
\hline 4 & 152.67 & 14.37 & 36.39 & 116.28 & 90.82 & 61.85 & 14.52 & 94.13 \\
\hline 5 & 43.54 & 13.26 & 41.32 & 102.22 & 85.37 & 58.17 & 14.18 & 92.37 \\
\hline 6 & 125.82 & 11.34 & 39.19 & 86.63 & 74.79 & 51.03 & 13.56 & 90.11 \\
\hline 7 & 134.36 & 12.26 & 42.51 & 91.85 & 79.89 & 54.47 & 13.79 & 91.2 \\
\hline 8 & 161.90 & 14.59 & 55.40 & 106.50 & 96.34 & 65.56 & 14.83 & 90.11 \\
\hline 9 & 161.90 & 14.77 & 54.18 & 107.73 & 96.34 & 65.56 & 14.83 & 91.2 \\
\hline 10 & 161.90 & 14.77 & 51.23 & 110.68 & 96.34 & 65.56 & 14.83 & 91.2 \\
\hline 11 & 153.99 & 13.88 & 47.96 & 106.02 & 91.60 & 62.39 & 14.80 & 90.1 \\
\hline 12 & 144.92 & 13.14 & 45.85 & 99.07 & 86.18 & 58.73 & 14.46 & 90.6 \\
\hline 13 & 135.34 & 12.20 & 42.15 & 93.18 & 80.47 & 54.87 & 14.03 & 90.1 \\
\hline 14 & 149.91 & 13.76 & 46.72 & 103.19 & 89.20 & 60.72 & 13.95 & 91.7 \\
\hline 15 & 160.37 & 14.45 & 56.75 & 103.62 & 95.43 & 64.94 & 14.52 & 90.11 \\
\hline 16 & 161.90 & 14.68 & 53.35 & 108.55 & 96.34 & 65.56 & 14.83 & 90.6 \\
\hline 17 & 143.54 & 12.93 & 49.09 & 94.45 & 85.37 & 58.17 & 14.18 & 90.1 \\
\hline 18 & 143.54 & 12.78 & 54.76 & 88.78 & 85.37 & 58.17 & 14.18 & 89.03 \\
\hline 19 & 119.96 & 10.88 & 44.45 & 75.50 & 71.33 & 48.62 & 12.16 & 90.6 \\
\hline 20 & 134.36 & 11.54 & 54.93 & 79.43 & 79.89 & 54.47 & 13.79 & 85.9 \\
\hline 21 & 161.90 & 14.24 & 60.00 & 101.91 & 96.34 & 65.56 & 14.83 & 87.9 \\
\hline 22 & 164.84 & 14.50 & 60.19 & 104.65 & 98.07 & 66.77 & 15.43 & 87.9 \\
\hline 23 & 153.99 & 13.88 & 50.74 & 103.24 & 91.60 & 62.39 & 14.80 & 90.11 \\
\hline 24 & 136.42 & 12.00 & 45.29 & 91.13 & 81.10 & 55.31 & 14.28 & 87.9 \\
\hline 25 & 123.85 & 11.09 & 41.12 & 82.74 & 73.63 & 50.22 & 13.09 & 89.5 \\
\hline
\end{tabular}

Fig. 9. March 2011, Relaxation after extra systole.

The treatment course was continued. In two months, ECG was almost normal. No extra systoles were detected. MV = 7.72 liters. 


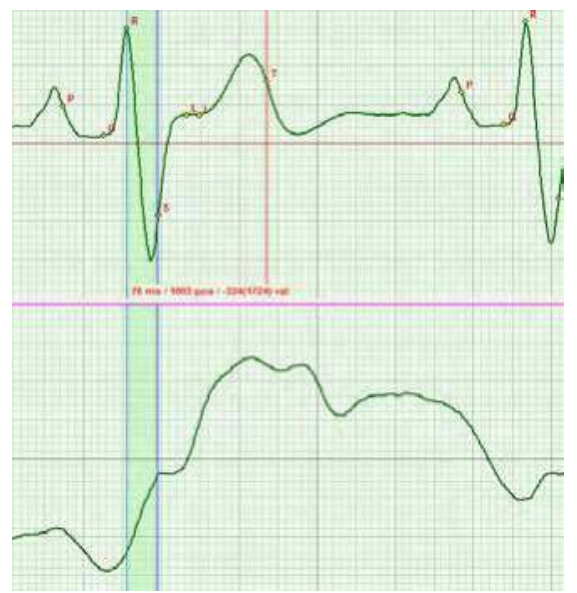

\begin{tabular}{|l|r|r|r|r|r|r|r|r|}
\hline \multicolumn{7}{|c|}{ PHASE ANALYSIS RESULTS } \\
\hline & \multicolumn{7}{|c|}{ HEMODYNAMIC PARAMETERS } \\
\cline { 2 - 8 } & SV(m) & \multicolumn{1}{|c|}{ MV(l) } & PV1(mi) & PV2(ml) & PV3(ml) & PV4(m) & PV5(ml) & $\begin{array}{c}\text { HEART } \\
\text { RATE }\end{array}$ \\
\hline AVERAGE & 131.64 & 7.72 & 85.23 & 46.42 & 78.22 & 53.42 & 15.14 & 58.68 \\
\hline
\end{tabular}

\begin{tabular}{|c|r|r|r|r|r|r|r|r|}
\hline CYCLE Iㅇ & SV(ml) & MV(l) & PV1 $(\mathrm{ml})$ & PV2(ml) & PV3(ml) & PV4(ml) & PV5(ml) & $\begin{array}{c}\text { HEAPT } \\
\text { RATE }\end{array}$ \\
\hline 1 & 121.42 & 6.68 & 80.55 & 40.88 & 72.13 & 49.29 & 14.55 & 54.99 \\
\hline 2 & 131.13 & 7.85 & 84.32 & 46.81 & 77.91 & 53.21 & 15.02 & 59.86 \\
\hline 3 & 141.07 & 8.62 & 89.38 & 51.70 & 83.84 & 57.23 & 15.59 & 61.09 \\
\hline
\end{tabular}

Fig. 10. May 2011

\section{Conclusion}

Cardiac cycle phase analysis method allows tracking any changes of hemodynamics and functions of the cardiovascular system. It can be used to identify the original cause of pathologies and to efficiently monitor the treatment progress.

\section{References}

[1] Rudenko, M.; Voronova, O. \& Zernov. V. Innovation in cardiology. A new diagnostic standard establishing criteria of quantitative \& qualitative evaluation of main parameters of the cardiac \& cardiovascular system according to ECG and RHEO based on cardiac cycle phase analysis (for concurrent single-channel recording of cardiac signals from ascending aorta).

http://precedings.nature.com/documents/3667/version/1/html

[2] Leontieva I. \& Sukhorukov V. The implications of metabolic disorders in the genesis of cardiac myopathia and possible use of L-carnitine for therapeutic correction. . Saint Petersburg. Manuscript -2006.

[3] Vasilenko V. Kh., Feldman S. B., Khotrov N.N., Miocardyodistrophia. - Moscow. Medicine. - 1989. -272.

[4] Kushakovsky M.S. Metabolic cardiac diseases. Saint Petersburg. Manuscript -2000. 128. 


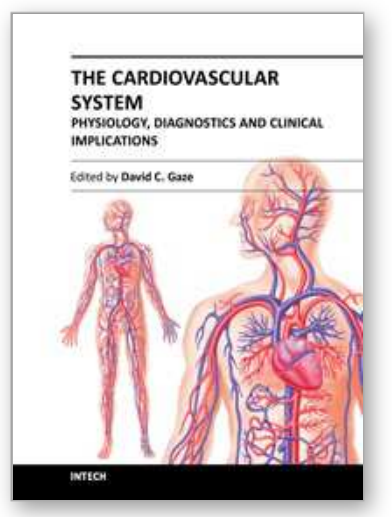

\author{
The Cardiovascular System - Physiology, Diagnostics and Clinical \\ Implications \\ Edited by Dr. David Gaze
}

ISBN 978-953-51-0534-3

Hard cover, 478 pages

Publisher InTech

Published online 25, April, 2012

Published in print edition April, 2012

The cardiovascular system includes the heart located centrally in the thorax and the vessels of the body which carry blood. The cardiovascular (or circulatory) system supplies oxygen from inspired air, via the lungs to the tissues around the body. It is also responsible for the removal of the waste product, carbon dioxide via air expired from the lungs. The cardiovascular system also transports nutrients such as electrolytes, amino acids, enzymes, hormones which are integral to cellular respiration, metabolism and immunity. This book is not meant to be an all encompassing text on cardiovascular physiology and pathology rather a selection of chapters from experts in the field who describe recent advances in basic and clinical sciences. As such, the text is divided into three main sections: Cardiovascular Physiology, Cardiovascular Diagnostics and lastly, Clinical Impact of Cardiovascular Physiology and Pathophysiology.

\title{
How to reference
}

In order to correctly reference this scholarly work, feel free to copy and paste the following:

Yury Fedosov, Stanislav Zhigalov, Mikhail Rudenko, Vladimir Zernov and Olga Voronova (2012). Interrelation Between the Changes of Phase Functions of Cardiac Muscle Contraction and Biochemical Processes as an Algorithm for Identifying Local Pathologies in Cardiovascular System, The Cardiovascular System - Physiology, Diagnostics and Clinical Implications, Dr. David Gaze (Ed.), ISBN: 978-953-51-0534-3, InTech, Available from: http://www.intechopen.com/books/the-cardiovascular-system-physiology-diagnostics-and-clinicalimplications/interrelation-between-the-changes-of-phase-functions-of-cardiac-muscle-contraction-andbiochemical-p

\section{INTECH}

open science | open minds

\section{InTech Europe}

University Campus STeP Ri Slavka Krautzeka 83/A

51000 Rijeka, Croatia

Phone: +385 (51) 770447

Fax: +385 (51) 686166

www.intechopen.com

\section{InTech China}

Unit 405, Office Block, Hotel Equatorial Shanghai

No.65, Yan An Road (West), Shanghai, 200040, China 中国上海市延安西路65号上海国际贵都大饭店办公楼 405 单元

Phone: +86-21-62489820

Fax: $+86-21-62489821$ 
(C) 2012 The Author(s). Licensee IntechOpen. This is an open access article distributed under the terms of the Creative Commons Attribution 3.0 License, which permits unrestricted use, distribution, and reproduction in any medium, provided the original work is properly cited. 